\title{
ТЕНДЕНЦИИ ПРОЯВЛЕНИЙ ЭЙДЖИЗМА В СОВРЕМЕННОЙ ОРГАНИЗАЦИИ
}

\section{TRENDS OF AGEISM IN THE MODERN ORGANIZATION}

O. Ivanova

T. Kurbatskaya

Summary. The employees who have reached the pre-retirement age are an important part of the labour population of Russia. Their experience, knowledge, skills and competencies qualitatively increase the labour potential of Russians. The labour activities of pre-retirement age employees is becoming the subject of close attention of employers, legislators, lawyers, sociologists, and doctors. This article is devoted to the issue of the effectiveness of professional activities of pre-retirement age employees.

Keywords: ageism, effectiveness of professional activities, factors, diagnostics, corporation, methods, research.

\author{
Иванова Ольга Алексеевна \\ Российский университет транспорта (г. Москва) \\ o.ivanova-1985@mail.ru \\ Курбацкая Татьяна Борисовна \\ К.nсх.н., дочент, Московский университет \\ им. С.Ю. Витте; дочент, Российский университет \\ транспорта \\ alterego123@yandex.ru
}

Аннотация. Работники, достигшие предпенсионного возраста, составляют важную часть трудового населения России. Их опыт, знания, навыки и компетенции качественно повышают трудовой потенциал россиян. Трудовая деятельность сотрудников предпенсионного возраста становится предметом пристального внимания работодателей, законодателей, юристов, социологов, медиков. Данная статья посвящена вопросу эффективности профессиональной деятельности сотрудников предпенсионного возраста.

Ключевые слова: эйджизм, эффективность профессиональной деятельности, факторы, диагностика, корпорация, методы, исследование.

ний в демографической структуре, но и как следствие изменений происходящих в русле пенсионного законодательства [18].

В ходе анализа литературы удалось выявить симптомы эйджизма, характерные для сотрудников предпенсионного возраста, а затем скомплектовать их в пять блоков, каждый из которых включает в себя вопросы по конкретным кейсам проявления эйджизма в компании:

1. Блок 1 - ущемление прав на самовыражение:

- издевки и подшучивания коллег с упоминаем возраста;

- несерьезное отношение к коллегам из-за возраста;

- подарки или сюрпризы от коллег, неприятно намекающие на возраст;

- присвоение коллегам неприятных прозвищ, связанных с возрастом;

- неуважительное отношение к коллегам на работе из-за возраста.

2. Блок 2 - ограничение социальных коммуникаций:

- сокрытие важной информации о компании и делах коллектива, обусловленное возрастным признаком;

- ограничения в участии в корпоративных мероприятиях из-за возраста; 
Таблица 1. Согласованность мнений респондентов по проблеме эйджизма

\begin{tabular}{|l|l|l|l|}
\hline Критерий & Коэф. конкордации & $\mathbf{X}^{2}$ & Оценка значимости \\
\hline Ущемление прав на самовыражение & 0,04 & 1,14 & Не значимо \\
\hline Ограничение социальных коммуникаций & 0,27 & 7,43 & Не значимо \\
\hline Ограничение профессионального роста & 0,55 & 15,43 & 3начимо \\
\hline Претензии к качеству работы & 0,87 & 24,23 & 3начимо \\
\hline Негативное влияние на здоровье & 0,60 & 16,91 & 3начимо \\
\hline
\end{tabular}

Таблица 2. Показатели коэффициента конкордации (Кк) в блоке «Ущемление прав на самовыражение»

\begin{tabular}{|c|c|c|c|c|c|}
\hline Проблема & $M$ & V & $\bar{x}$ & $\sigma$ & $\Sigma$ \\
\hline $\begin{array}{l}\text { Издевки и подшучивания коллег } \\
\text { с упоминаем возраста }\end{array}$ & 0,49 & 43,03 & 3,00 & 1,29 & 21,00 \\
\hline $\begin{array}{l}\text { Несерьезное отношение к коллегам } \\
\text { из-за возраста }\end{array}$ & 0,75 & 57,99 & 3,43 & 1,99 & 24,00 \\
\hline $\begin{array}{l}\text { Подарки или сюрпризы от коллег, } \\
\text { неприятно намекающие на возраст }\end{array}$ & 0,46 & 42,52 & 2,86 & 1,21 & 20,00 \\
\hline $\begin{array}{l}\text { Присвоение коллегам неприятных } \\
\text { прозвищ, связанных с возрастом }\end{array}$ & 0,55 & 46,58 & 3,14 & 1,46 & 22,00 \\
\hline $\begin{array}{l}\text { Неуважительное отношение } \\
\text { к коллегам на работе из-за возраста }\end{array}$ & 0,53 & 54,34 & 2,57 & 1,40 & 18,00 \\
\hline
\end{tabular}

- дистанционирование от общения с коллективов возрастных сотрудников;

- игнорирование жалоб и пожеланий возрастных сотрудников относительно комфорта внутри коллектива;

- формирование недоброжелательных друг к другу мини-групп внутри коллектива.

3. Блок 3 - ограничения профессионального роста:

- отказ в повышении по должности из-за возраста;

- ограничения поездок/командировок по работе из-за возраста;

- пренебрежение к сотрудникам со стороны руководства;

- пренебрежение к сотрудникам со стороны коллектива;

- отказ в повышении заработной платы из-за возраста.

4. Блок 4 - претензии к качеству работы:

- игнорирование инициатив и жалоб возрастных сотрудников;

- отсутствие или отказ от инструктирования;

- доносительство относительно качества работы;

- придирки со стороны руководства относительно качества труда;

- загрузка возрастных сотрудников слишком сложной работой.
5. Блок 5 - негативное влияние на здоровье:

- применение физической силы в сторону возрастных сотрудников;

- необоснованная чрезмерная загрузка;

- ухудшение условий труда возрастных сотрудников;

- создание гнетущей и стрессовой атмосферы;

- отказ в социальной поддержке, предусмотренной в соцпакете.

Для выяснения степени согласованности мнений экспертов мы использовали коэффициент конкордации (Кк), расчет которого осуществлялся по методике, предложенной И.Г. Венецким и В.И. Венецкой, М. Кендэлом и Б. Смитом. Далее была проведена интерпретация полученных данных в ходе исследования. Данные, полученные в ходе исследования представлены в таблице 1.

Согласно данным таблицы 1 выявлена статистически значимая согласованность мнений в том, что у сотрудников имеются ярко выраженные проблемы по факторам претензий к качеству их работы, негативного влияния на здоровье, а также ограничения профессионального роста, т.е. значительная часть сотрудников отмечают, что сталкивались с одними и теми же видами возрастной дискриминации в процессе своей трудовой деятельности. 
Таблица 3. Вычисление коэффициента конкордации (Кк) в блоке «Ограничение социальных коммуникаций»

\begin{tabular}{|c|c|c|c|c|c|}
\hline Проблема & $M$ & V & $\bar{x}$ & $\sigma$ & $\Sigma$ \\
\hline $\begin{array}{l}\text { Сокрытие важной информации } \\
\text { о компании и делах коллектива }\end{array}$ & 0,42 & 29,96 & 3,71 & 1,11 & 26,00 \\
\hline $\begin{array}{l}\text { Ограничения в участии } \\
\text { в корпоративных мероприятиях } \\
\text { из-за возраста }\end{array}$ & 0,57 & 55,12 & 2,71 & 1,50 & 19,00 \\
\hline $\begin{array}{l}\text { Дистанционирование от общения } \\
\text { с коллективом возрастных } \\
\text { сотрудников }\end{array}$ & 0,42 & 33,86 & 3,29 & 1,11 & 23,00 \\
\hline $\begin{array}{l}\text { Игнорирование жалоб } \\
\text { и пожеланий возрастных } \\
\text { сотрудников }\end{array}$ & 0,47 & 73,12 & 1,71 & 1,25 & 12,00 \\
\hline $\begin{array}{l}\text { Формирование } \\
\text { недоброжелательных друг к другу } \\
\text { мини-групп внутри коллектива }\end{array}$ & 0,57 & 42,33 & 3,57 & 1,51 & 25,00 \\
\hline
\end{tabular}

\section{Блок 1- Ущемление прав на самовыражение}

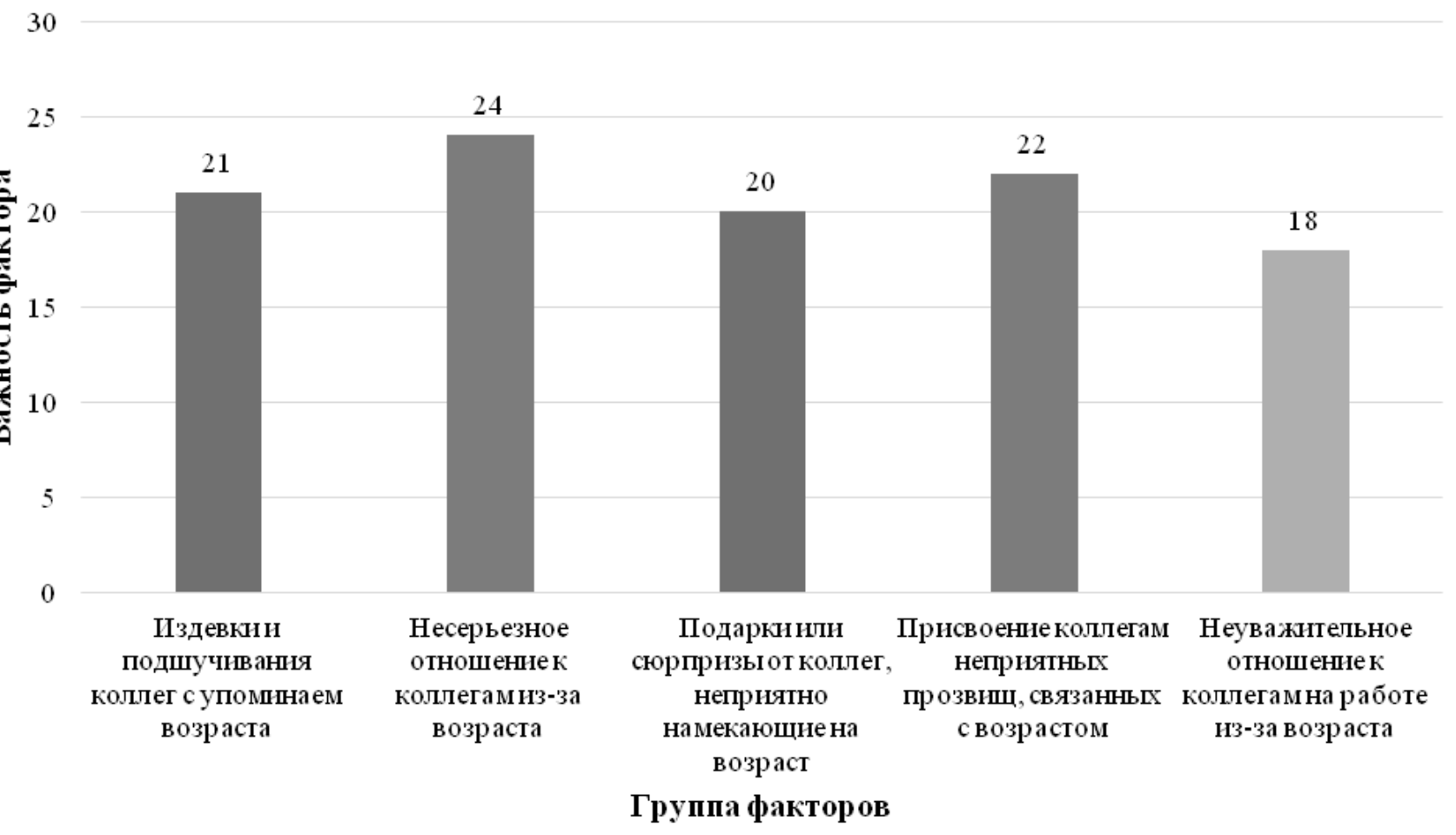

Рис. 1. Показатели факторов блока «Ущемление прав на самовыражение» 


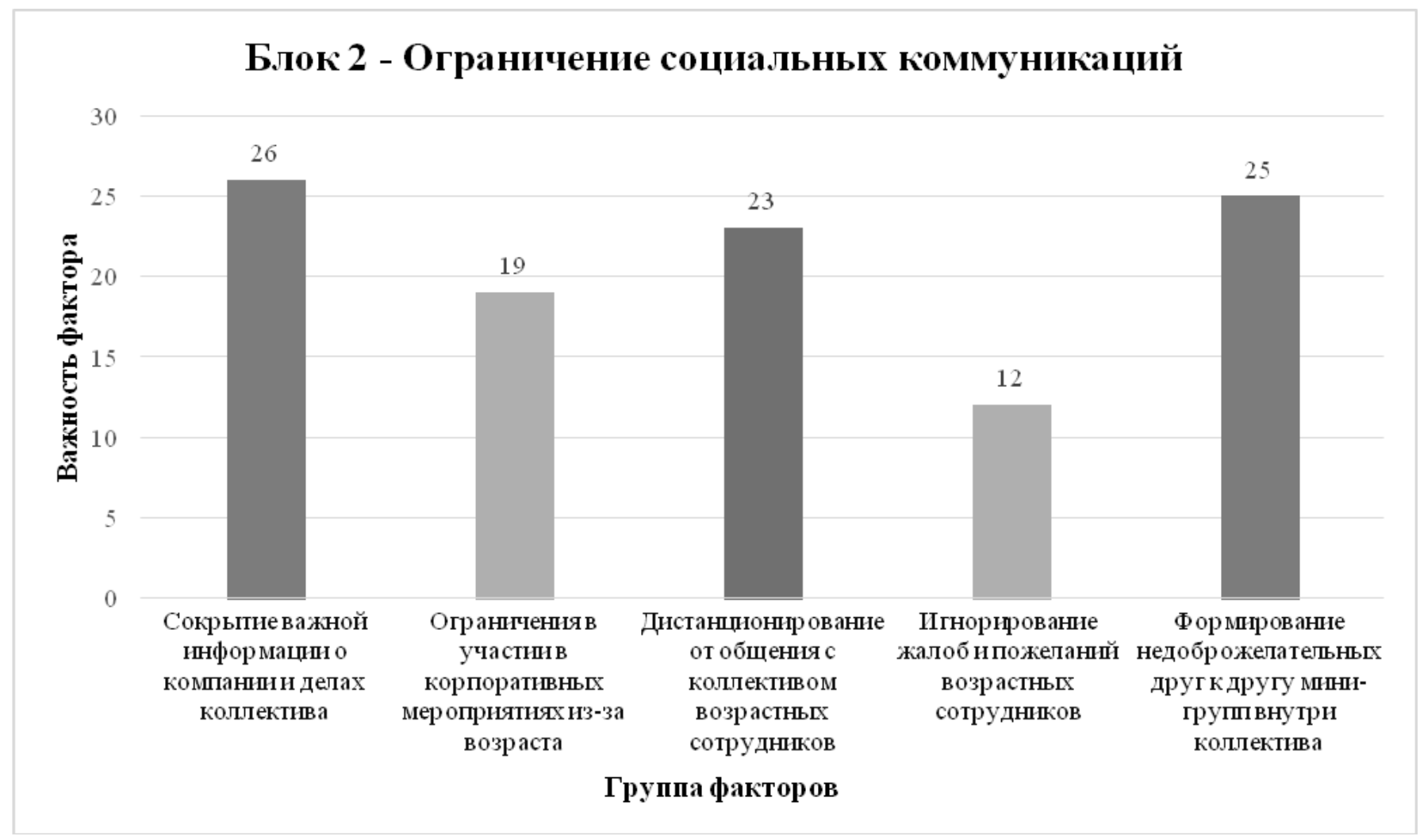

Рис. 2. Показатели факторов блока «Ограничение социальных коммуникаций»

По проблеме ограничения социальных коммуникаций и ущемления прав по возрастному признаку сотрудники не имеют согласованного мнения, что свидетельствует о том, что они по-разному относятся к данному критерию в процессе своей профессиональной деятельности.

Согласно данным таблицы 2 наиболее распространенной проблемой среди возрастных сотрудников является несерьезное отношение к коллегам из-за возраста. На наш взгляд, причиной этому может стать преобладание в коллективе молодых сотрудников над возрастными. Это вызывает разрозненность интересов, подходов к работе.

Наименее распространенной проблемой респонденты выбрали неуважительное отношение на работе из-за возраста.

Наиболее значимыми проблемами в блоке № 1 для сотрудников подразделения являются несерьезное отношение к коллегам из-за возраста (24) и присвоение коллегам неприятных прозвищ, связанных с возрастом (22). К средне выраженным проблемам сотрудники относят издевки и подшучивания с упоминанием возраста (21), подарки, неприятно намекающие на возраст (20).
По данным таблицы 3 самой значимой проблемой респондентов стало сокрытие важной информации о компании и делах коллектива. Это может быть вызвано общей неосведомленностью сотрудников относительно корпоративной культуры и внутренних изменений в компании.

Наименее значимой респонденты выбрали игнорирование жалоб и пожеланий возрастных сотрудников.

Наиболее значимыми проблемами в блоке № 2 для сотрудников являются сокрытие важной информации о компании и делах коллектива (26), формирование недоброжелательных друг к другу мини-групп внутри коллектива (25). К средне выраженным проблемам сотрудники относят дистанционирование от общения с коллективом возрастных сотрудников (23). Ограничения в участии в корпоративных мероприятиях из-за возраста (19) и игнорирование жалоб и пожеланий возрастных сотрудников (12) сотрудники отнесли к наименее выраженной проблеме.

Резюмируя данные таблицы видно, что наиболее значимой проблемой респонденты выделили отказ в повышении по должности из-за возраста. Причиной этого может быть недостаточный уровень квалификации сотрудников, несвоевременность прохождения 
Таблица 4. Вычисление коэффициента конкордации (Кк) в блоке «Ограничение профессионального роста»

Блок 3 - Ограничение профессионального роста
\begin{tabular}{|l|l|l|l|l|l|} 
Проблема & $\mathbf{M}$ & $\mathbf{V}$ & $\mathbf{X}$ & $\boldsymbol{\sigma}$ & $\boldsymbol{\Sigma}$ \\
\hline $\begin{array}{l}\text { Отказ в повышении } \\
\text { по должности из-за возраста }\end{array}$ & 0,30 & 17,77 & 4,43 & $\mathbf{0}, 79$ & 31,00 \\
\hline $\begin{array}{l}\text { Ограничения поездок/ } \\
\text { командировок по работе из-за } \\
\text { возраста }\end{array}$ & 0,46 & 65,42 & 1,86 & 1,21 & 13,00 \\
\hline $\begin{array}{l}\text { Пренебрежение к сотрудникам } \\
\text { со стороны руководства }\end{array}$ & 0,37 & 28,46 & 3,43 & 0,98 & 24,00 \\
\hline $\begin{array}{l}\text { Пренебрежение к сотрудникам } \\
\text { со стороны коллектива }\end{array}$ & 0,18 & 28,46 & 1,71 & 0,49 & 12,00 \\
\hline $\begin{array}{l}\text { Отказ в повышении заработной } \\
\text { платы из-за возраста }\end{array}$ & 0,53 & 39,12 & 3,57 & 1,40 & 25,00 \\
\hline
\end{tabular}

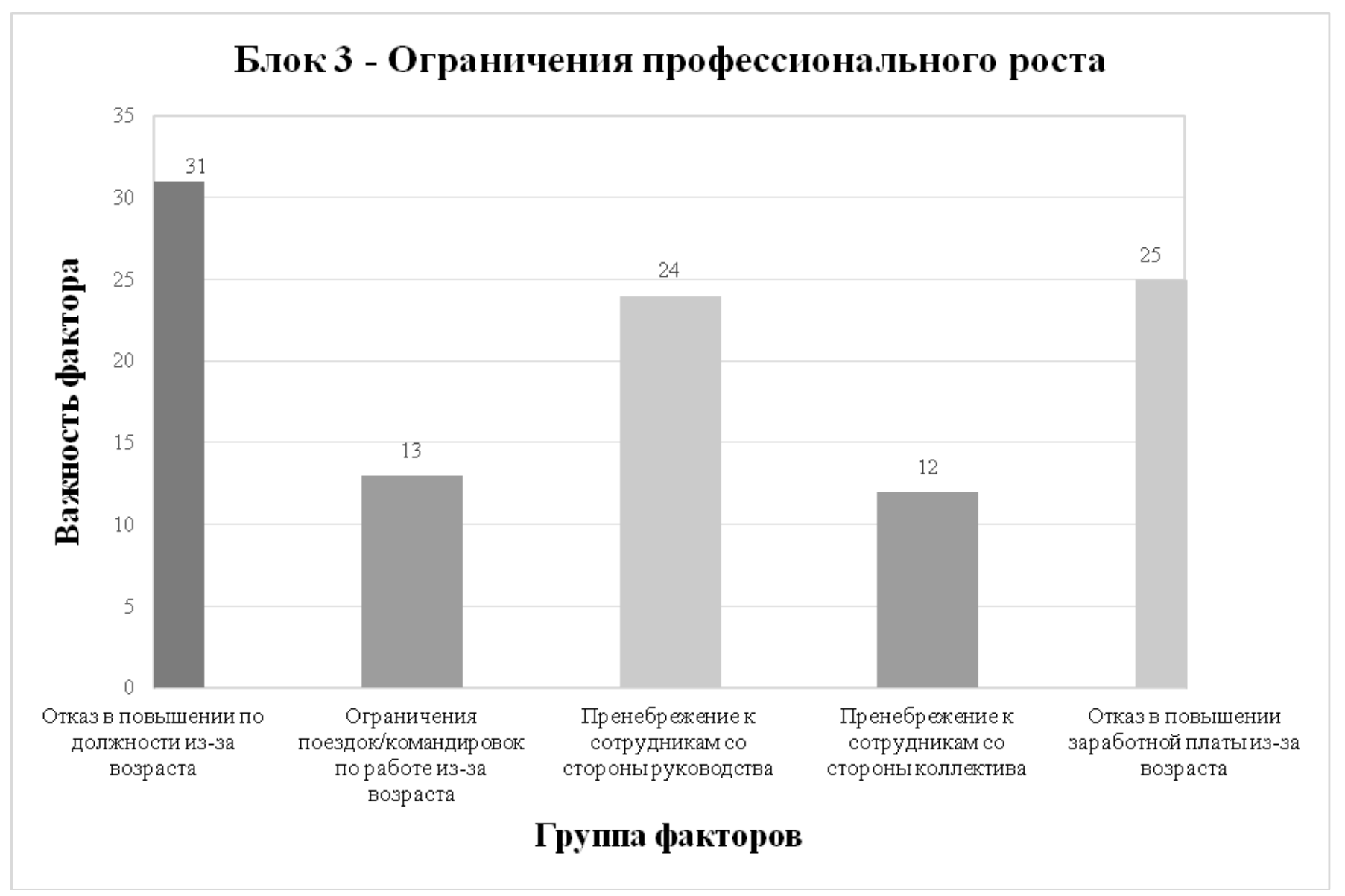

Рис. 3. Показатели факторов блока «Ограничение профессионального роста»

курсов повышения квалификации или вовсе отказ от их прохождения.

Наиболее значимой проблемой в блоке № 3 для сотрудников является отказ в повышении по должности из-за возраста (31). К средне выраженным проблемам сотрудники относят пренебрежение к сотрудникам со стороны руководства (24) и отказ в повышении заработной платы из-за возраста (25). Ограничения поездок по работе из-за возраста (13) и пренебрежение к сотрудникам со стороны коллектива (12) отнесли к наименее выраженной проблеме. 
Таблица 5. Вычисление коэффициента конкордации (Кк) в блоке «Претензии к качеству работы»

\begin{tabular}{|c|c|c|c|c|c|}
\hline \multicolumn{6}{|c|}{ Блок 4 - Претензии к качеству работы } \\
\hline Проблема & M & V & $\bar{X}$ & $\sigma$ & $\Sigma$ \\
\hline $\begin{array}{l}\text { Игнорирование инициатив } \\
\text { и жалоб возрастных сотрудников }\end{array}$ & 0,29 & 33,07 & 2,29 & 0,76 & 16,00 \\
\hline $\begin{array}{l}\text { Отсутствие или отказ } \\
\text { от инструктирования }\end{array}$ & 0,14 & 33,07 & 1,14 & 0,38 & 8,00 \\
\hline $\begin{array}{l}\text { Доносительство относительно } \\
\text { качества работы }\end{array}$ & 0,20 & 20,79 & 2,57 & 0,53 & 18,00 \\
\hline $\begin{array}{l}\text { Придирки со стороны } \\
\text { руководства относительно } \\
\text { качества труда }\end{array}$ & 0,20 & 12,07 & 4,43 & 0,53 & 31,00 \\
\hline $\begin{array}{l}\text { Загрузка возрастных сотрудников } \\
\text { слишком сложной работой }\end{array}$ & 0,20 & 11,69 & 4,57 & 0,53 & 32,00 \\
\hline
\end{tabular}

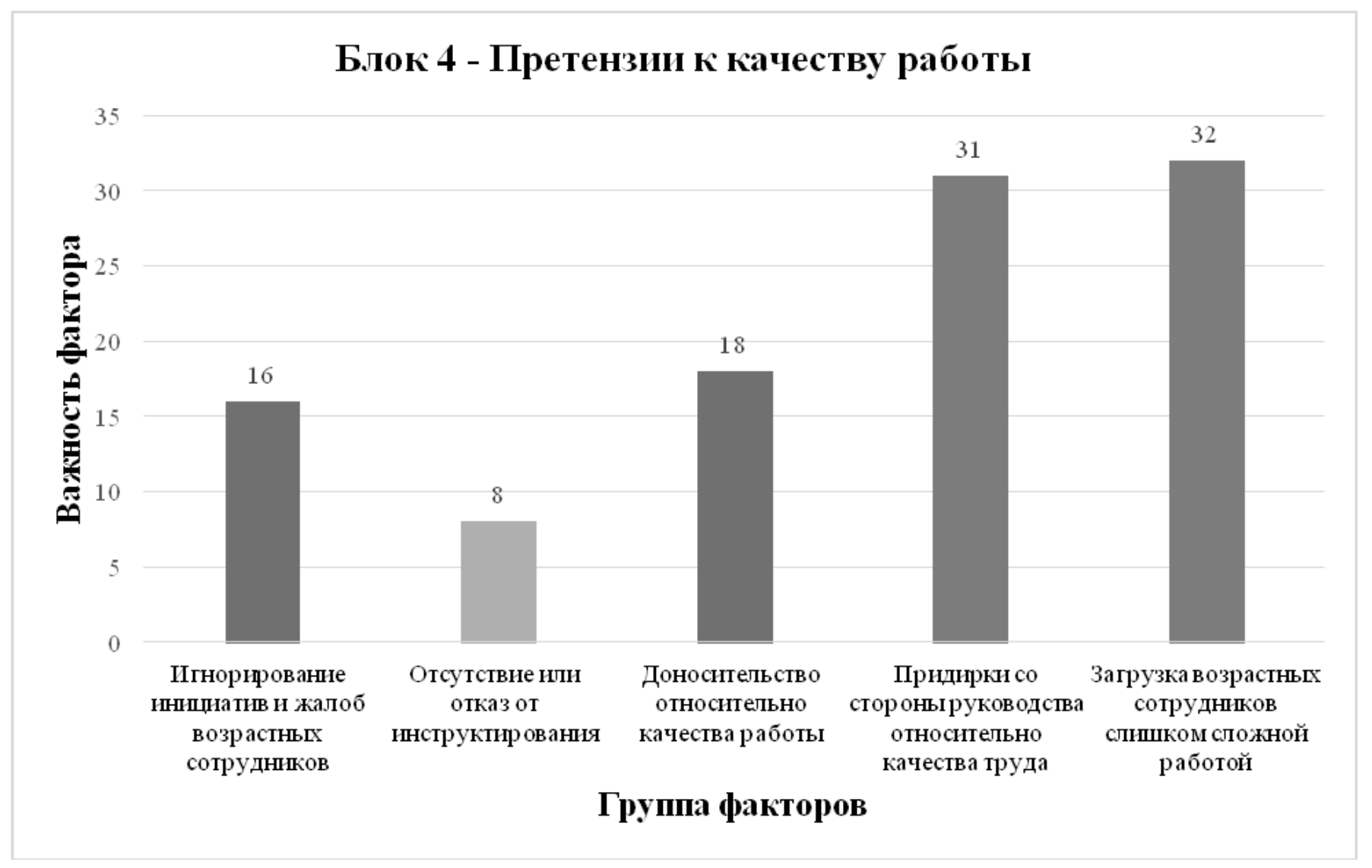

Рис. 4. Показатели факторов блока «Претензии к качеству работы»

Наиболее значимой проблемой респондентов стали придирки руководства относительно качества труда. Возможной причиной может стать отсутствие у подчиненных правильного понимания о своей роли и функциональных обязанностях, либо объективная нехватка знаний для текущего исполнения задач. Самым низким с точки зрения значимости респонденты выдели отказ от инструктирования.
Наиболее значимыми проблемами в блоке № 4 для сотрудников являются придирки со стороны руководства относительно качества труда (31) и загрузка возрастных сотрудников слишком сложной работой (32). К средне выраженным проблемам сотрудники относят игнорирование инициатив и жалоб возрастных сотрудников (16) и доносительство относительно качества работы (18). Отсутствие или отказ инструктирования (8) 
Таблица 6. Вычисление коэффициента конкордации (Кк) в блоке «Негативное влияние на здоровье»

\begin{tabular}{|c|c|c|c|c|c|}
\hline Проблема & $M$ & V & $\bar{X}$ & $\sigma$ & $\Sigma$ \\
\hline $\begin{array}{l}\text { Применение физической } \\
\text { силы в сторону возрастных } \\
\text { сотрудников }\end{array}$ & 0,00 & 0,00 & 1,00 & 0,00 & 7,00 \\
\hline $\begin{array}{l}\text { Необоснованная чрезмерная } \\
\text { загрузка }\end{array}$ & 0,31 & 27,22 & 3,00 & 0,82 & 21,00 \\
\hline $\begin{array}{l}\text { Ухудшение условий труда } \\
\text { возрастных сотрудников }\end{array}$ & 0,46 & 29,33 & 4,14 & 1,21 & 29,00 \\
\hline $\begin{array}{l}\text { Создание гнетущей } \\
\text { и стрессовой атмосферы }\end{array}$ & 0,26 & 17,09 & 3,06 & 0,69 & 27,00 \\
\hline $\begin{array}{l}\text { Отказ в социальной поддержке, } \\
\text { предусмотренной в соцпакете }\end{array}$ & 0,53 & 47,14 & 3,00 & 1,41 & 21,00 \\
\hline
\end{tabular}

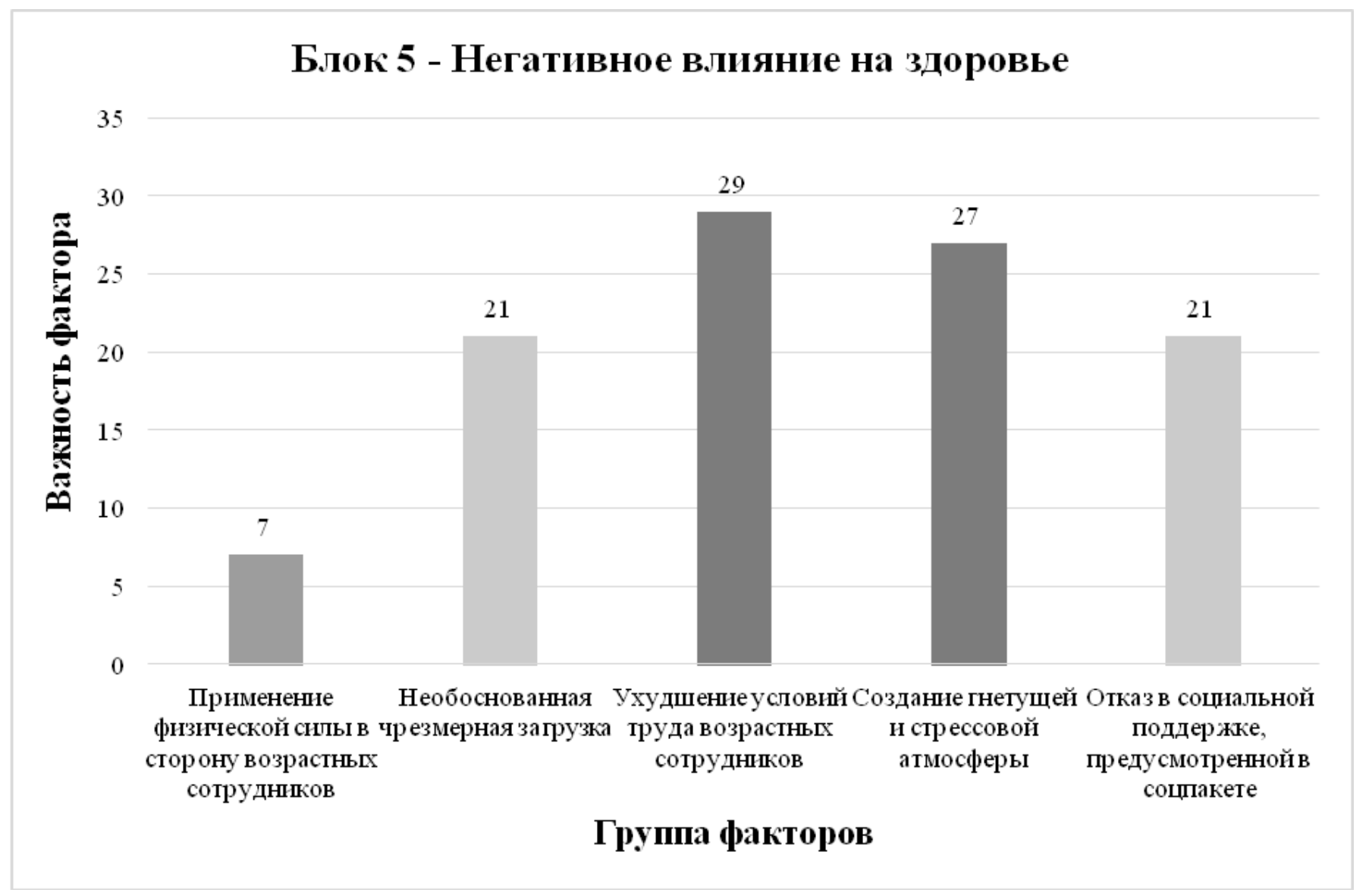

Рис. 5. Показатели факторов блока «Негативное влияние на здоровье»

сотрудники отнесли к наименее выраженной проблеме.

Наиболее выраженной проблемой в блоке стало ухудшение условий труда. Причинами этого могут стать объективное несоблюдение норм и порядков организации рабочего пространства и процесса. Наименее выра- женной проблемой респонденты выделили применение физической силы, откуда следует, что подобного рода дискриминация не применяется в сторону сотрудников.

Наиболее значимыми проблемами в блоке № 5 для сотрудников являются ухудшение условий труда возрастных сотрудников (29) и создание гнетущей и стрес- 


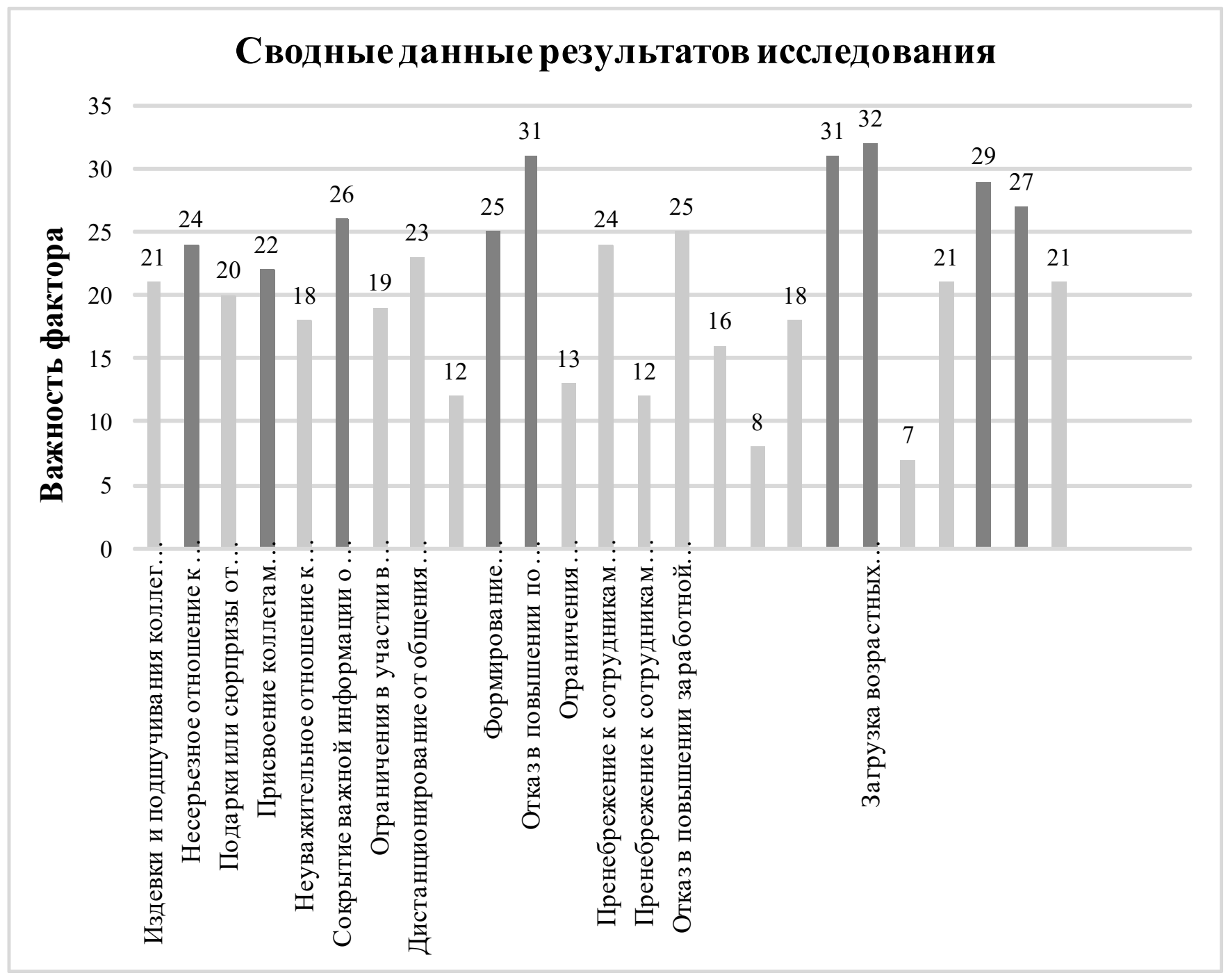

Рис. 6. Сводные данные результатов исследования

совой атмосферы (27). Ксредне выраженнымпроблемам сотрудники в равной степени относят необоснованную чрезмерную загрузку и отказ в соцподдержке, предусмотренной в соцпакете (21). Применение физический силы в сторону возрастных сотрудников (7) сотрудники отнесли к наименее выраженной проблеме.

На рисунке 6 отражены все искомые факторы эйджизма в организации, красным цветом выделены 9 наиболее значимых симптомов эйджизма для респондентов. В их число входит: несерьезное отношение к коллегам из-за возраста и присвоение коллегам неприятных прозвищ, связанных с возрастом; сокрытие важной информации о компании и делах коллектива; формирование недоброжелательных друг к другу мини-групп внутри коллектива; отказ в повышении по должности из-за возраста; придирки со стороны руководства относительно качества труда и загрузка возрастных сотрудников слишком сложной работой; ухудшение условий труда возрастных сотрудников. В дальнейшем на базе этих симптомов будет построена программа и рекомендации по преодолению эйджизма в подразделении.

Рассмотрим возможные причины возникновения наиболее значимых проблем из пяти блоков для сотрудников подразделения:

1. несерьезное отношение к коллегам из-за возраста и присвоение коллегам неприятных прозвищ, связанных с возрастом. Данные проблемы носят психологический характер, поэтому выделены в один пункт и рассмотрены как комплексная система. Они могут быть вызваны одной из следующих причин: разрозненность коллектива и его расслоение на «возрастных» и «молодых» сотрудников; личностная несовместимость или неприязнь одних членов коллектива к другим. Также во взаимоот- 
ношениях внутри коллектива имеет место связка «руководитель - подчиненный», когда речь идет об уровне корпоративной культуры внутри компании, стиле управления группой, уровне вовлеченности руководителя в психологический климат внутри коллектива. Вероятно, руководящий состав дирекции уделяет недостаточно много внимания вопросу психологического климата, либо не обладает информацией о его проблемах;

2. сокрытие важной информации о компании и делах коллектива. Недостаточная информационная осведомленность коллектива «более опытных сотрудников» можетбыть следствиемвсеобщей неосведомленности среди всех членов подразделения - вероятно, их молодые коллеги обладают корпоративными знаниями не в большей степени, чем первые. Это может быть вызвано не выстроенными процессами передачи обратной связи от руководителей к подчиненным - отсутствием регулярных собраний, игнорированием вопросов сотрудников и т.д.;

3. формирование недоброжелательных друг к другу мини-групп внутри коллектива. Одной из возможных причин разногласий и расслаивания коллектива на группы может являться разность интересов и амбиций. Также в силу существующей тенденции среди «возрастных» сотрудников, выражающейся в нежелании регулярного повышения своей квалификации, обучения новым подходам и рабочим программам, их подход к работе, уровень вовлеченности в процесс и мотивация значительно отличаются от более молодых коллег, что способствует возникновению различных барьеров в коммуникации и трудовой деятельности. Как следствие, возникает дискоммуникация между разными стратами;

4. отказ в повышении по должности из-за возраста.

В дирекции наблюдается тенденция к тому, что «возрастные» сотрудники не проявляют инициативы и часто отказываются от возможностей для повышения своей квалификации, тренингов и обучающих курсов, предоставляемых компанией. Сотрудники, регулярно не повышающие уровень своей квалификации, имеют меньше шансов успешного прохождения ежегодной аттестации, в результате которой сотрудник может получить линейное или финансовое повышение;

5. придирки со стороны руководства относительно качества труда и загрузка возрастных сотрудни- ков слишком сложной работой. Данные проблемы также объединены в общий блок, т.к. причины из возникновения, как и пути решения, могут пересекаться и быть комплексными. Вероятно, данная проблема вытекает из проблемы, описанной в прошлом пункте. В силу несвоевременного или отказа от прохождения курсов повышения квалификации, обучения новым программам и т.д. «возрастные» сотрудники находят поручаемые им задачи трудными, выходящими за рамки их привычного функционала. Исполнение таких задач сотрудником без нужных навыков может требовать определенного качества реализации и занимать более долгие сроки, чем было заложено на них изначально. В случае выхода за рамки сроков руководство может применить санкции или вынести выговор. Еще одной из возможных причин может выступать объективный фактор неправильный формат передачи руководителем обратной связи по результатам оценки труда своих подчиненных. Это может быть резкая, грубая форма выражения, отсутствие конструктивной критики, переход на личности и т.д.

6. ухудшение условий труда возрастных сотрудников.

Работа в удобном для сотрудника помещении (правильная планировка, хорошее освещение, доступ к необходимым канцелярским товарам и технике, эргономика рабочего места и т.д.) в значительной степени влияет на чувство комфорта в процессе трудовой деятельности. Сюда также входит распределение ценностей по группе, доход, премии и надбавки. Важна сбалансированность этого распределения [15].

7. создание гнетущей и стрессовой атмосферы.

Данные проблемы также являются следствием всех ранее обозначенных факторов - разрозненность коллектива на «возрастных» и «молодых» сотрудников, отсутствие стремления к получению новых знаний и применения их для автоматизации трудовой деятельности у некоторых сотрудников, критика со стороны руководства и т.д. В совокупности эти факторы могут служить созданию общей нездоровой атмосферы, снижать мотивацию к трудовой деятельности, способствовать появлению комплексов, ощущения «ненужности».

Для решения данных проблем требуется комплексная программа и рекомендации по борьбе с эйджизмом.

\section{ЛИТЕРАТУРА}

1. КоАП РФ Статья 5.62. Дискриминация (введена Федеральным законом от 07.12.2011 N420-Ф3)

2. КоАП РФ Статья 13.11.1. Распространение информации о свободных рабочих местах или вакантных должностях, содержащей ограничения дискриминационного характера (введена Федеральным законом от 02.07.2013 N162-Ф3) 
3. Конвенция N111 Международной организации труда «Относительно дискриминации в области труда и занятий» (принята в г. Женеве 25.06 .1958 на 42-й сессии Генеральной конференции МОТ)

4. Трудовой кодекс Российской Федерации» от 30.12.2001 N197-Ф3 (ред. от 31.07.2020) (с изм. и доп., вступ. в силу с 13.08.2020)

5. Белецкая Е.А., Сергеева Е.М., Харьковская Е.В. Социально-культурная деятельность с людьми третьего возраста как условие преодоления эйджизма: региональный аспект // Научно-методический электронный журнал «Концепт».— Т. 11. — 2019._ С. 389-390.

6. Габрук В.В., Шлычкова М.В. Негативные геронтостереотипы населения и проблема социальной активизации пожилых людей // Современные исследования социальных проблем. - № 5 (37). - 2018.—C. 1-15.

7. Горелик С.Г., Колпина Л.В., Реутов Е.В. Социологический анализ геронтологического эйджизма в учреждениях здравоохранения и социальной защиты Белгородской области // Научные ведомости БелГУ. Серия: Медицина. Фармация. 2019. № 18. 56 с.

8. Городова Т.В., Колпина Л.В. Теоретические основы исследования геронтологического эйджизма // Современные проблемы науки и образования. 2019. № 1-1. 25 c.

9. Ж Журавлева И.В. Эффекты возраста интервьюера // Вестник ИГЭУ. 2018. Вып.1. 11-13 с.

10. Клепикова Е. Эйджизм на российском рынке труда: дискриминация в заработной плате, 2017-88 C.

11. Колпина Л.В. Эйджизм в восприятии пожилых людей и его влияние на социальное здоровье населения пожилого и старческого возраста // Вестник Всероссийского общества специалистов по медико-социальной экспертизе, реабилитации и реабилитационной индустрии. - 2018. — № 4.— C. 74-81.

12. Козина И.М. Возрастная дискриминация при приеме на работу. Дискриминация на рынке труда: современные проявления, факторы и практики преодоления. М.: Институт экономики РАН; 2017. - 50-62.

13. Колпина Л. Эйджизм в сферах здравоохранения и социальной защиты, 2015-115 С.

14. Конли Ч. Лекарство от эйджизма, 2018-3С.

15. Миловидова Галина, Горовцова Маргарита. Информационно правовой портал. СанПиН для офисных работников, 2017, [Электронный ресурс] URL: http://www.garant.ru/ia/aggregator/?tag_id=2503 (дата обращения 02.12.2020).

16. Ageism Amplifies Cost and Prevalence of Health Conditions Леви Б., 2020 г.

17. Федеральная служба государственной статистики: Ситуация на рынке труда в таблицах, графиках, диаграммах, 2020 год. [Электронный ресурс] URL: https://rosstat.gov.ru/ (дата обращения 22.03.2020).

18. Организация Объединенных наций. Демографические изменения. [Электронный ресурс] URL: https://www.un.org/ru/un75/shifting-demographics (дата обращения 22.08.2020).

19. Эйджизм в управлении персоналом современной организации [Электронный ресурс] URL: https://studopedia.info/3-85485.html (дата 0бращения 01.05.2020).

20. Горелик С.Г., Колпина Л.В., Реутов Е.В. Социологический анализ геронтологического эйджизма в учреждениях здравоохранения и социальной защиты Белгородской области // Научные ведомости БелГУ. Серия: Медицина. Фармация. 2019. № 18. 56 с.

21. Киселева Н.А., Люди пожилого возраста как объект социальной работы // Научно-методический электронный журнал «Концепт».— № 1 (январь). — 2018. - C. 31-35.

( ) Иванова Ольга Алексеевна ( o.ivanova-1985@mail.ru ), Курбацкая Татьяна Борисовна ( alterego123@yandex.ru ).

Журнал «Современная наука: актуальные проблемы теории и практики» 